\title{
Proteína degradável no rúmen associada a fontes de amido de alta ou baixa degradabilidade: digestibilidade in vitro e desempenho de novilhos em crescimento
}

\author{
Saul Ferreira Caldas Neto, Lúcia Maria Zeoula ${ }^{2}$, Ricardo Kazama ${ }^{3}$, Ivanor Nunes do Prado², \\ Luiz Juliano Valério Geron ${ }^{4}$, Fábio Cortez Leite de Oliveira ${ }^{3}$, Odimari Pricila Pires do Prado ${ }^{3}$ \\ ${ }^{1}$ Centro de Ensino Superior de Maringá (Cesumar) - PR. \\ 2 Universidade Estadual de Maringá (UEM) - PR, Av. Colombo, 5790, CEP: 87020-900. Bolsista do CNPq. \\ 3 Pós-graduando em Produção Animal pela Universidade Estadual de Maringá (UEM) - PR. Bolsista do CNPq \\ ${ }^{4}$ DZO/UNEMAT - Universidade do Estado do Mato Grosso - Av. Mato Grosso, Caixa postal 181, CEP: 78250-000, Pontes e Lacerda - MT.
}

RESUMO - Objetivou-se avaliar os efeitos de teores crescentes de proteína degradável no rúmen $(\mathrm{PDR}=47,52$, 57 e $62 \%$ ) associados a fontes de amido de baixa (milho) ou de alta (farinha de varredura de mandioca - FVM) degradabilidade ruminal em rações com 50:50\% volumoso:concentrado sobre a digestibilidade in vitro da MS (DIVMS) e o ganho de peso de novilhos em crescimento. Para determinação da DIVMS, foi utilizada a técnica de dois estádios de Tilley \& Terry (1963). As médias obtidas para a DIVMS foram submetidas às análises de variância e regressão em função do teor de PDR da ração. Para o ensaio de desempenho animal, foram utilizados 32 novilhos mestiços (Nelore x Red Angus), não-castrados (275 kg de PV), alojados em duplas, em delineamento experimental inteiramente casualizado. Não foi observado efeito do teor de PDR de dietas contendo milho sobre a DIVMS, indicando que não houve deficiência de nitrogênio e que, possivelmente, a digestibilidade da fonte de amido (milho) foi o fator limitante. Observou-se efeito quadrático do teor de PDR sobre a DIVMS para as dietas contendo FVM, o que indica a ocorrência do efeito de sincronização entre a disponibilidade de energia e nitrogênio, permitindo aumento da atividade microbiana nos níveis mais elevados de PDR na ração e melhor utilização da energia proveniente da fonte de amido de alta degradabilidade ruminal. Não foi observado efeito dos diferentes teores de PDR e da fonte de amido de alta degradabilidade ruminal sobre o consumo de MS, o ganho de peso médio e a conversão alimentar dos animais.

Palavras-chave: farinha de varredura de mandioca, fermentação, milho, sincronização

\section{Rumen degradable protein associated to starch sources of different ruminal degradability: in vitro digestibility and performance of growing steers}

\begin{abstract}
The objective of this study was to evaluate the effects of increasing levels of rumen-degradable protein $(\mathrm{RDP}=47,52,57$ and 62\%) associated to starch sources of low (corn) and high (cassava by-product (CBP) ruminal degradability on in vitro DM digestibility (IVDMD) and average daily gain of growing steers. In vitro DM digestibility was determined by using the Tilley and Terry (1963) technique. The in vitro data was submitted to analysis of variance and regression analysis in function of dietary RDP levels. The in vivo trial was conducted using 32 crossbred steers (Nellore $x$ Red Angus) averaging $275 \mathrm{~kg}$ of body weight and fed diets with 50:50 forage:concentrate ratio. Animals were housed in pairs and assigned to treatments according to a completely randomized design. No effect of increasing RDP levels was observed on IVDMD on diets supplemented with corn indicating no lack of nitrogen. Thus, corn digestibility appeared to be the limiting factor on IVDMD. A significant quadratic effect was found for IVDMD by increasing the RDP levels on diets supplemented with CBP suggesting that a better synchronization between energy availability and ammonia release improved microbial growth, which increased the efficiency of energy and RDP utilization on diets with high RDP. It was not observed effect of different RDP levels associated to a starch source rapidly degraded in the rumen onDM intake, average daily gain, and feed conversion on feedlot steers.
\end{abstract}

Key Words: cassava by-product meal, corn, fermentation, synchronization

\section{Introdução}

Os microrganimos ruminais dependem de fontes de energia e nitrogênio fermentáveis para sua atividade meta- bólica, influenciando fortemente a digestibilidade ruminal e, conseqüentemente, o fluxo de nutrientes, tanto de ácidos graxos voláteis quanto de proteína microbiana, para o ruminante. 
As proteínas ingeridas pelo ruminante podem sofrer atividade proteolítica ruminal, sendo os aminoácidos desaminados e sua terminação amino liberada na forma de amônia, que pode ser absorvida pela parede do rúmen, escapar para o intestino ou ser utilizada na síntese de aminoácidos microbianos.

Dependendo da fonte protéica utilizada, alguns aminoácidos podem escapar da atividade microbiana e ser absorvidos diretamente no intestino delgado. Desta forma, o aporte de aminoácidos para o intestino delgado pode ser formado tanto de aminoácidos provenientes da dieta quanto de aminoácidos microbianos sintetizados a partir de diversas fontes de nitrogênio, tanto exógenas quanto endógenas.

A utilização de fontes de proteína de baixa degradabilidade ruminal acarreta aumento no fluxo de aminoácidos para o intestino delgado (Commer et al., 1993; Zinn \& Owens, 1993). Assim, considerando a exigência de aminoácidos de um animal em crescimento, as fontes de proteína de baixa degradabilidade ruminal poderiam acarretar melhores resultados produtivos, pois a perda de aminoácidos no rúmen em forma de amônia poderia ser minimizada desde que a fonte de baixa degradabilidade apresentasse valor biológico superior ao da fonte de proteína microbiana.

A utilização de dietas ricas em carboidratos, principalmente de fontes de alta degradabilidade associadas à degradabilidade das fontes protéicas, pode originar situações com excesso de energia e deficiência de nitrogênio para a ferme ntação ruminal. $O$ excesso de energia acaba sendo utilizado apenas para a manutenção microbiana, sem gerar efeitos nos processos de síntese e crescimento da microbiota e até mesmo acarretando a utilização de ciclos fúteis para eliminação do excesso de carboidratos (Russel, 1998).

A sincronização entre as fontes de carboidratos (que forneceriam energia e esqueletos carbônicos para os microrganismos) e as de nitrogênio pode acarretar maximização da eficiência microbiana e diminuição da perda de nitrogênio em forma de amônia e da energia dos carboidratos, promovendo melhoria na digestão da MS, especialmente da fração fibrosa. $\mathrm{O}$ aumento na eficiência microbiana permitiria au mento na disponibilidade de proteína microbiana para ser absorvida no intestino, suprindo, assim, as exigências de animais em crescimento.

Os objetivos neste trabalho foram avaliar o efeito do nível de proteína degradável no rúmen (PDR) em dietas formuladas com uma fonte de amido de baixa e de alta degradabilidade ruminal sobre a digestibilidade in vitro da MS e o efeito do nível de PDR em dietas contendo uma fonte de amido de alta degradabilidade ruminal sobre o ganho de peso de novilhos em crescimento.

\section{Material e Métodos}

O experimento foi conduzido nas instalações dos setores de Bovinocultura de Leite e de Corte da Fazenda Experimental de Iguatemi (FEI) e no Laboratório de Análise de Alimentos e Nutrição Animal (LANA), pertencentes ao Departamento de Zootecnia da Universidade Estadual de Maringá (UEM).

Foram utilizados 32 novilhos mestiços, não-castrados, com 18 meses de idade e $275 \mathrm{~kg}$ de PV, alojados em duplas em baias de $5 \times 2 \mathrm{~m}$. O par alocado em cada baia recebeu o mesmo tratamento. As baias eram cercadas com vergalhões de ferro, com piso de concreto, parcialmente cobertas com telhas de zinco e possuíam cocho de alimentação $(2 \mathrm{~m}$ lineares/baia) na parte coberta e bebedouro $(250 \mathrm{~L})$ na parte descoberta.

Os alimentos utilizados para compor as rações foram: feno de aveia como fonte de volumoso, farelos de algodão e de soja, farinha de peixe e uréia como fonte de nitrogênio, farinha de varredura de mandioca e milho como fonte de energia (Tabela 1).

Para o ensaio de digestibilidade in vitro da MS (DIMS), foram formuladas oito dietas experimentais (Tabela 2), com relação 50:50 volumoso:concentrado, isoprotéicas e isoenergéticas, com teores crescentes de PDR (47, 52, 57 e 62\%), de modo que quatro dietas continham milho como fonte energética de baixa degradabilidade ruminal e quatro continham farinha de varredura de mandioca como fonte energética de alta degradabilidade ruminal (Zeoula \& Caldas Neto, 2001). Foi utilizada uma vaca leiteira fistulada no rúmen consumindo uma dieta com relação 50:50 (volumoso:concentrado) para retirada do líquido ruminal, obtido antes da alimentação matinal e acondicionado em garrafa térmica previamente aquecida com água a $39^{\circ} \mathrm{C}$.

Para o ensaio de DIVMS, cada dieta experimental (quatro teores de PDR) foi produzida em duplicata para servir de repetição. Em cada ensaio de digestibilidade, cada dieta foi incubada também em duplicata, sendo realizadas duas corridas, perfazendo um total de 64 amostras dedietas incubadas. As dietas foram moídas utilizando-se peneira de crivo de 1,0 mm. Também foram adicionados em cada ensaio uma forragem índice (feno de aveia) e três tubos contendo apenas líquido de rúmen+saliva artificial para servirem como branco. 
Tabela 1- Composição química dos alimentos (\% da MS)

Table 1 - Chemical composition of the feeds (\% of DM)

Nutriente $(\% \mathrm{MS})$

Nutrient (\%DM)

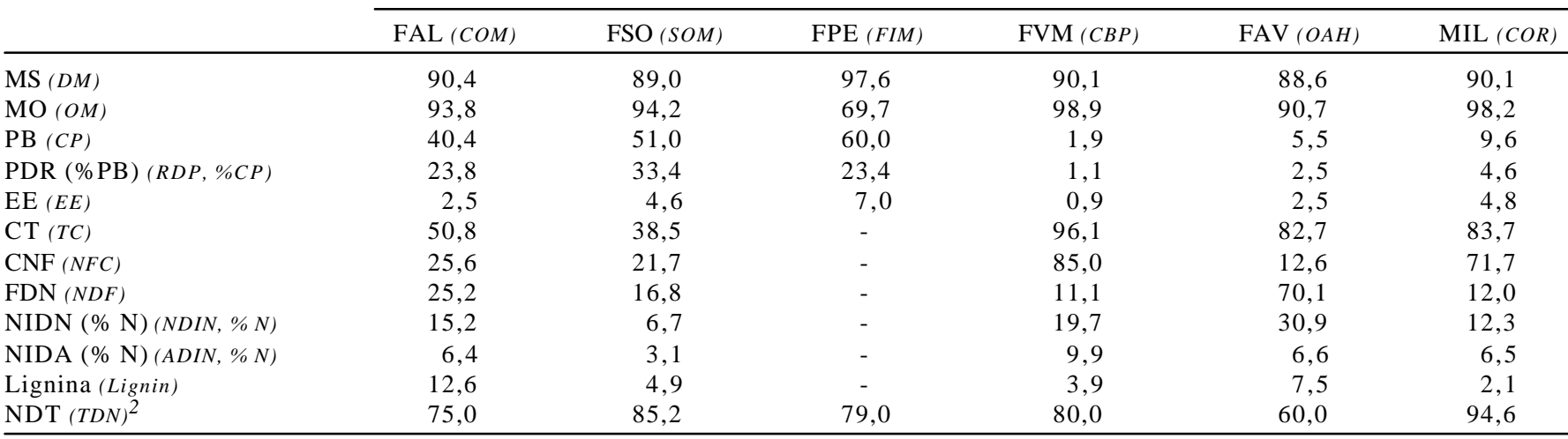

${ }^{1}$ FAL: farelo de algodão; FSO: farelo de soja; FPE: farinha de peixe; FVM: farinha de varredura de mandioca; FAV: feno de aveia; MIL: milho. PDR: proteína degradável no rúmen dos alimentos estimada pelo método in situ, NIDN: nitrogênio insolúvel em detergente neutro; NIDA: nitrogênio insolúvel em detergente ácido. ${ }^{2}$ NDT dos alimentos, obtido de tabelas (NRC, 1996; Valadares Filho et al., 2002).

${ }^{1}$ COM: cottonseed meal; SOM: soybean meal; FIM: fish meal; CBM: cassava by-product meal; OAH: oat hay; COR: corn. RDP: rumen-degradable protein -estimated by in situ studies; NDIN: neutral detergent insoluble nitrogen; ADIN: acid detergent insoluble nitrogen. ${ }^{2}$ TDN of feeds obtained by NRC (1996) and Valadares Filho et al. (2002) tables.

A digestibilidade in vitro da MS foi determinada pela técnica de dois estádios, de Tilley \& Terry (1963), evitando-s e, contudo, a segunda centrifugação, de acordo com as modificações descritas por Silva \& Queiroz (2002).

O líquido de rúmen foi misturado à saliva artificial com um pipetador automático mantido em banho-maria, a $39^{\circ} \mathrm{C}$, durante o processo de incubação. Após a inoculação, os tubos foram incubados em estufa a $39^{\circ} \mathrm{C}$, sendo agitados 2 , 4, 6, 8, 12, 16, 24 e 36 horas após a incubação para permitir o escape dos gases formados, repetindo-se esse processo na segunda etapa após a adição da pepsina e ácido clorídrico.

Após as duas etapas de incubação, os tubos foram centrifugados a $2.000 \mathrm{rpm}$ e o sobrenadante foi retirado com uma bomba de sucção. Os tubos foram colocados em estufa a $105^{\circ} \mathrm{C}$ por 24 horas e pesados para a determinação do resíduo. A determinação da digestibilidade (\% da amostra incubada) foi realizada da seguinte forma:

Digestibilidade $=($ resíduo do tubo - resíduo do branco $)$ total incubado

Para o ensaio de desempenho animal, foram formuladas quatro dietas com teores de proteína degradável no rúmen (PDR) de 55, 60, 65 e 70\% (\%PB) e com fonte energética de alta degradabilidade ruminal (farinha de varredura de mandioca) (Tabela 3). As dietas foram balanceadas para serem isoenergéticas e isoprotéicas (12\% de PB e $69 \%$ de NDT) e apresentavam mesma relação volumoso:concentrado de 50:50 e teores de FDN semelhantes.

Para o ensaio de desempenho, os novilhos foram previamente vacinados contra febre aftosa, vermifugados com produto à base de ivermectina e identificados com brincos de plásticos na orelha direita.
O experimento foi realizado entre os meses de maio e julho (60 dias de duração), sendo dividido em dois períodos. Antes do período experimental, foi realizado um período de adaptação de 30 dias para adaptação dos animais às instalações, ao manejo e às rações experimentais. Este cuidado foi tomado pelo fato de que os animais foram estabulados em duplas, podendo gerar conflitos ou estresse, o que poderia afetar os resultados. Além disso, todas as dietas tinham como fonte energética a farinha de varredura de mandioca, de elevada degradabilidade ruminal, o poderia acarretar distúrbios fermentativos nos animais, principalmente em virtude da ausência de aditivos como ionóforos e tamponantes nas dietas esses produtos também poderiam afetar o metabolismo do nitrogênio no rúmen. O nível de concentrado foi aumentado gradualmente até atingir o nível determinado para cada tratamento, quando, então, foi iniciado o período experimental.

Os animais foram alimentados duas vezes ao dia ( 8 e $16 \mathrm{~h}$ ). O concentrado e o feno foram pesados separadamente e misturados diretamente nos comedouros. O concentrado foi utilizado na forma farelada, enquanto o feno foi triturado em picadeira para permitir melhor mistura ao concentrado e diminuir a seleção pelos animais e a perda de alimento nos comedouros.

Antes do fornecimento diário da ração matinal, as sobras do dia anterior foram pesadas para cálculo do consumo diário. As amostras das sobras e dos alimentos fornecidos foram acondicionadas em sacos plásticos, identificadas por tratamento, por baia e por animal e congeladas a $-20^{\circ} \mathrm{C}$ para posterior análise. 
Tabela 2 - Composição química e percentual das dietas experimentais

Table 2 - Chemical and ingredient composition of experimental diets

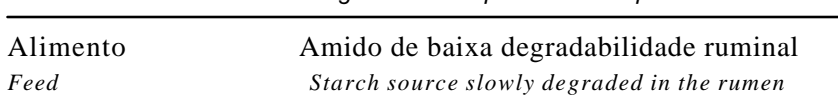

\begin{tabular}{lllll}
\cline { 2 - 4 } & PDR 47\% & PDR 52\% & PDR 57\% & PDR 62\%
\end{tabular}

\begin{tabular}{lcccc} 
& $47 \% R D P$ & $52 \% R D P$ & $57 \% R D P$ & $62 \% R D P$ \\
\hline $\begin{array}{l}\text { Farelo algodão } \\
\text { Cottonseed meal }\end{array}$ & 5,3 & 14,4 & - & - \\
$\begin{array}{l}\text { Farelo de soja } \\
\text { Soybean meal }\end{array}$ & - & 0,5 & 9,2 & 3,6 \\
$\begin{array}{l}\text { Farinha de peixe } \\
\text { Fish meal }\end{array}$ & 5,8 & - & - & - \\
$\begin{array}{l}\text { Milho } \\
\text { Corn }\end{array}$ & 37,7 & 36,4 & 36,2 & 45,0 \\
$\begin{array}{l}\text { Uréia } \\
\text { Urea }\end{array}$ & - & - & 0,3 & 1,2 \\
$\begin{array}{l}\text { Feno de aveia } \\
\text { Oat hay }\end{array}$ & 51,2 & 49,0 & 53,5 & 50,0 \\
\hline
\end{tabular}

Nutriente (\%MS)

Nutrient (\%DM)

\begin{tabular}{|c|c|c|c|c|}
\hline$\% \mathrm{MS}(\% D M)$ & 89,8 & 89,7 & 88,5 & 88,2 \\
\hline$\% \mathrm{MO}(\% O M)$ & 92,5 & 93,9 & 93,8 & 94,3 \\
\hline$\% \mathrm{~PB}(\% C P)$ & 12,0 & 12,3 & 11,9 & 12,2 \\
\hline$\% \operatorname{PDR}(\% R D P)$ & 46,7 & 52,9 & 57,7 & 63,9 \\
\hline$\% \operatorname{EE}(\% E E)$ & 3,6 & 3,4 & 3,5 & 3,6 \\
\hline$\%$ FDN ( $\% N D F)$ & 41,8 & 42,4 & 43,4 & 41,1 \\
\hline$\% \mathrm{CT}(\% T C)$ & 76,6 & 78,5 & 78,1 & 80,4 \\
\hline$\% \mathrm{CNF}(\% N F C)$ & 35,0 & 36,1 & 34,7 & 39,4 \\
\hline \multirow[t]{2}{*}{$\%$ NDT $(\% T D N)$} & 75,0 & 75,1 & 74,2 & 75,6 \\
\hline & \multicolumn{4}{|c|}{$\begin{array}{l}\text { Amido de alta degradabilidade ruminal } \\
\text { Starch source rapidly degraded in the rumen }\end{array}$} \\
\hline Farelo algodão & - & 12,2 & 17,9 & 4,0 \\
\hline $\begin{array}{l}\text { Cottonseed meal } \\
\text { Farelo de soja }\end{array}$ & 4,0 & 3,0 & 1,6 & 10,6 \\
\hline $\begin{array}{l}\text { Soybean meal } \\
\text { Farinha de peixe } \\
\text { Fish meal }\end{array}$ & 10,4 & 4,0 & - & - \\
\hline $\mathrm{FVM}^{1}$ & 31,5 & 30,9 & 30,2 & 32,5 \\
\hline $\begin{array}{l}\text { Cassava by-product } \\
\text { Uréia }\end{array}$ & - & - & 0,3 & 0,9 \\
\hline $\begin{array}{l}\text { Urea } \\
\text { Feno de aveia } \\
\text { Oathay }\end{array}$ & 54,0 & 50,0 & 50,3 & 52,3 \\
\hline
\end{tabular}

Nutriente (\%MS)

Nutrient (\%DM)

\begin{tabular}{lrrrr}
\hline$\%$ MS (\% DM) & 89,9 & 89,7 & 89,7 & 89,6 \\
\% MO (\%OM) & 91,3 & 92,9 & 93,8 & 93,9 \\
\% PB (\% CP) & 11,9 & 12,2 & 12,2 & 12,9 \\
\% PDR (\% RDP) & 46,1 & 52,7 & 58,9 & 66,2 \\
\% EE (\% EE) & 2,6 & 2,3 & 2,1 & 2,2 \\
\% FDN (\% NDF) & 42,0 & 42,1 & 43,4 & 43,0 \\
\% CT (\% TC) & 76,5 & 78,4 & 80,3 & 80,6 \\
\% CNF (\% NFC) & 34,7 & 36,5 & 36,9 & 37,5 \\
\% NDT (\% TDN) & 69,2 & 69,6 & 69,1 & 69,4 \\
\hline
\end{tabular}

${ }^{1} \mathrm{FVM}=$ farinha de varredura de mandioca.

As amostras de alimentos e as sobras foram posteriormente secas em estufa a $55^{\circ} \mathrm{C}$ por 96 horas e moídas (peneira com crivo de $1 \mathrm{~mm}$ ). As amostras diárias foram misturadas, formando amostras compostas por baia (tratamento) e por período.
Tabela 3 - Composição química e percentual das dietas com fonte de amido de alta degradabilidade ruminal utilizadas no ensaio de desempenho animal

Table 3 - Ingredient and chemical composition of experimental diets with starch source rapidly degraded in the rumen used in the in vivo trial

\begin{tabular}{|c|c|c|c|c|}
\hline \multirow[t]{2}{*}{$\begin{array}{l}\text { Ingrediente }(\% \mathrm{MS}) \\
\text { Feed }(\% D M)\end{array}$} & \multicolumn{4}{|c|}{$\begin{array}{c}\text { Dieta (\% PDR) } \\
\text { Diet }(\% \text { RDP })\end{array}$} \\
\hline & 55 & 60 & 65 & 70 \\
\hline $\begin{array}{l}\text { Farelo de algodão } \\
\text { Cottonseed meal }\end{array}$ & - & 13,67 & 1,31 & - \\
\hline Farelo de soja & 9,90 & 6,14 & 14,82 & 13,02 \\
\hline $\begin{array}{l}\text { Soybean meal } \\
\text { Farinha de peixe } \\
\text { Fish meal }\end{array}$ & 6,15 & - & - & - \\
\hline $\begin{array}{l}\text { Farinha de varredura } \\
\text { Cassava by-product }\end{array}$ & 32,15 & 28,30 & 31,80 & 34,40 \\
\hline $\begin{array}{l}\text { Feno de aveia } \\
\text { Oat hay }\end{array}$ & 50,00 & 50,00 & 50,00 & 50,00 \\
\hline $\begin{array}{l}\text { Sal mineral } \\
\text { Mineral salt }\end{array}$ & 1,80 & 1,80 & 1,80 & 1,80 \\
\hline $\begin{array}{l}\text { Uréia } \\
\text { Urea } \\
\end{array}$ & - & 0,10 & 0,30 & 0,80 \\
\hline \multicolumn{5}{|l|}{$\begin{array}{l}\text { Nutriente (\%MS) } \\
\text { Nutrient }(\% D M)\end{array}$} \\
\hline$\% \mathrm{MS}(\% D M)$ & 88,7 & 87,7 & 87,6 & 87,7 \\
\hline$\% \mathrm{MO}(\% O M)$ & 92,6 & 93,8 & 94,1 & 94,2 \\
\hline$\% \mathrm{~PB}(\% C P)$ & 12,1 & 12,2 & 12,3 & 12,2 \\
\hline$\% \operatorname{EE}(\% E E)$ & 2,4 & 2,1 & 2,3 & 2,2 \\
\hline$\% \operatorname{FDN}(\% N D F)$ & 40,3 & 42,7 & 41,4 & 41,1 \\
\hline$\% \operatorname{PDR}(\% R D P)$ & 52,4 & 58,3 & 62,5 & 66,6 \\
\hline$\%$ Lignina (\% Lignin) & 5,5 & 6,9 & 5,9 & 5,7 \\
\hline$\% \mathrm{CT}(\% T C)$ & 76,1 & 77,9 & 78,3 & 79,4 \\
\hline$\% \mathrm{CNF}(\% N F C)$ & 35,9 & 35,2 & 36,9 & 38,4 \\
\hline$\% \operatorname{NDT}(\% T D N)$ & 69,0 & 68,1 & 69,1 & 68,6 \\
\hline
\end{tabular}

Os animais foram pesados pela manhã, no início do período experimental, no final do período de adaptação (30 dias), aos 60 dias e ao final do período experimental (90 dias) para determinação do ganho médio diário individual dos animais. Os pesos dos animais também foram utilizados no cálculo do consumo individual dos animais em cada baia (\% PV), permitindo-se estimar a conversão alimentar (CA), visto que o consumo diário foi obtido por baia e não individualmente.

As amostras de alimentos e sobras foram analisadas para determinação do teor de MS, MO, PB, FDN, EE, CT e CNF. As determinações de MS, MO, PB e EE foram realizadas segundo procedimento padrão da AOAC, citado por Silva \& Queiroz (2002). A determinação da FDN foi realizada de acordo com a metodologia descrita por Van Soest et al. (1991). Os valores de CT foram calculados utilizando-se a seguinte fórmula: $\mathrm{CT}=\% \mathrm{MO}-\% \mathrm{~PB}-\% \mathrm{EE}$ e os valores de CNF estimados pela equação: $\mathrm{CNF}=\mathrm{CT}-$ FDN. A determinação da EB foirealizada por meio de bomba calorimétrica (Parr). 
Os valores de digestibilidade in vitro da MS das dietas contendo milho e daquelas contendo farinha de varredura de mandioca foram submetidos às análises de variância e regressão da digestibilidade da MS em função do nível de PDR da ração, utilizando-se o programa SAEG (Euclydes, 1983). As dietas com milho e aquelas com farinha de varredura de mandioca foram incubadas em épocas separadas, não havendo, portanto, um esquema fatorial fonte amido $\mathrm{x} \% \mathrm{PDR}$.

Utilizou-se um delineamento experimental inteiramente casualizado, com quatro tratamentos (níveis de PDR na ração - 55, 60, 65 e 70\%) e número de repetições dependente da unidade experimental. Como os animais foram alojados em duplas, o ganho médio diário foi obtido individualmente permitindo-se um número de oito repetições por tratamento. No caso do consumo de alimentos e da conversão alimentar, calculou-se o consumo individual em cada baia, considerando o peso vivo dos animais alojados, utilizando-se como unidade experimental a baia e descontando-se os graus de liberdade a elas referentes.

Os dados obtidos foram submetidos às análises de variância e regressão pelo programa SAEG (Euclydes, 1983) a 5\% de significância, utilizando-se o seguinte modelo estatístico:

$$
Y_{i j}=\mu+T_{i}+\operatorname{COV}(P I)+e_{i j},
$$

em que $Y_{i j}=$ observação no animal $\mathrm{j}$, ou baia $\mathrm{j}$, submetido ao nível de PDRi; $\mu=$ constante geral; $\mathrm{T}_{\mathrm{i}}=$ efeito do nível de PDRi; COV $(\mathrm{PI})$ = covariância em relação ao peso vivo inicial; $e_{i j}=$ erro aleatório associado a cada observação $Y_{i j}$.

\section{Resultados e Discussão}

Não foi observado efeito $(\mathrm{P}>0,05)$ do nível de PDR sobre a DIVMS para as dietas contendo milho, com média de 61,3\% (Figura 1a). Verificou-se, no entanto, efeito $(\mathrm{P}<0,05)$ quadrático do nível de PDR sobre a DIVMS para as dietas contendo farinha de varredura de mandioca, sendo obtida a equação $\hat{\mathrm{Y}}=65,4+0,12 * \mathrm{PDR}-0,00099 * \mathrm{PDR}^{2}$ com $\mathrm{R}^{2}=0,7$ (Figura 1b). A derivada da curva indicou a maior digestibilidade para o teor de 60,6\% de PDR.

Semelhante aos resultados observados, Chester-Jones et al. (1990) não notaram efeito da subtituição de uréia por farelo de soja sobre a digestibilidade da MS e o fluxo de nitrogênio microbiano de dietas contendo milho, determinados em meio de cultura contínua.

Fu et al. (2001), utilizando cultura de fluxo contínuo, avaliaram o efeito do aumento do nível de PDR (de 3,5 para $17,5 \%$ da MS) sobre a digestibilidade da MS e a síntese microbiana de dietas contendo milho como fonte energética. Esses autores não observaram efeito dos níveis de PDR sobre a digestibilidade da MS e da MO e a eficiência de síntese microbiana e concluíram que as exigências de nitrogênio dos microrganismos fermentadores de carboidratos não-estruturais foram atendidas em todos os níveis de PDR.

Klusmeyer et al. (1990), em estudo com vacas leiteiras, observaram que a substituição do farelo de soja por farinha de glúten de milho não teve efeito sobre o fluxo de nitrogênio microbiano para o intestino delgado. Do mesmo modo, Milton et al. (1997) não notaram efeito do fornecimento de fontes de nitrogênio com diferentes degradabilidades ruminais sobre o fluxo de nitrogênio microbiano em novilhos alimentados com dietas à base de milho.

Os resultados observados (in vitro e in vivo) na literatura (Chester-Jones et al., 1990; Klusmeyer et al., 1990; Milton et al., 1997; Fu et al., 2001) e neste estudo sugerem que a fonte de nitrogênio de alta ou baixa degradabilidade ruminal pouco afetou a digestibilidade da MS de dietas contendo milho, indicando que, nos níveis de PDR utilizados, o limitante para a degradabilidade ruminal da MS pode ser a disponibilidade de energia e não de nitrogênio. Caso fossem observadas diferenças na digestibilidade da MS, esses resultados indicariam melhoria principalmente na digestibilidade da FDN. Além disso, os resultados obtidos nesses trabalhos não indicaram aumento na produção de proteína microbiana, o que, possivelmente, teria ocorrido se

(a)

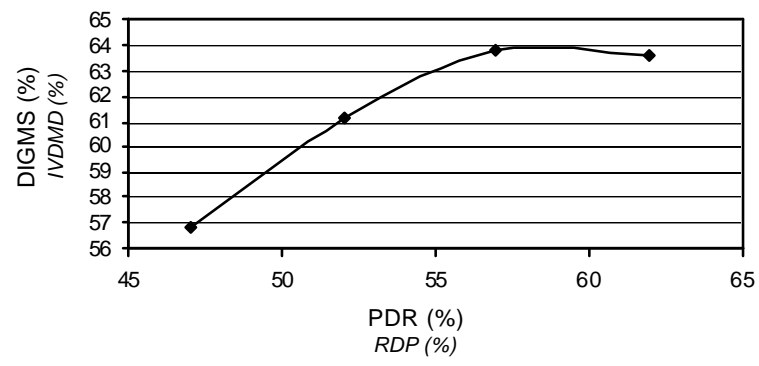

(b)

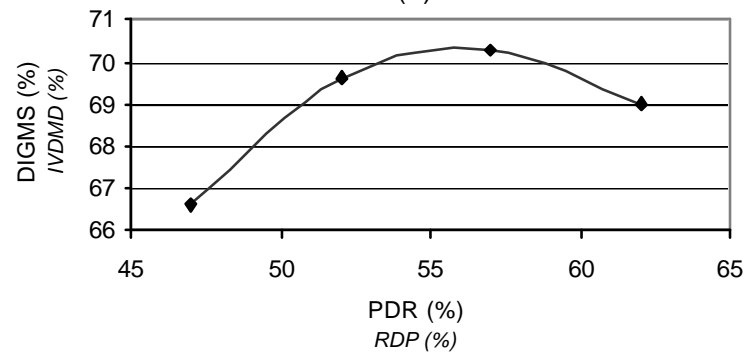

Figura 1 - Digestibilidade in vitro da MS, conforme o nível de proteína degradável no rúmen, de dietas contendo fonte de amido de baixa degradabilidade ruminal (a) e fonte de amido de alta degradabilidade ruminal (b)

Figure 1 - In vitro DM digestibility in response to increasing levels of dietary rumen-degradable protein: (a) starch source slowly degraded in the rumen; (b) starch source rapidly degraded in the rumen. 
o nitrogênio fosse limitante para a eficiência microbiana, ao contrário da energia. Nocek \& Russel (1988) observaram que o aumento de 0,04 para $0,25 / \mathrm{h}$ na taxa de degradação das fontes de carboidratos elevou a produção de biomassa microbiana de 0,26 para 0,37 g bactéria/g de carboidratos totais. Contudo, no caso da dieta com menor disponibilidade de nitrogênio no rúmen, a quantidade de nitrogênio foi insuficiente para suportar a máxima eficiência microbiana.

Hoover \& Stokes (1991), avaliando a digestibilidade in vitro, observaram aumento linear na produção de proteína microbiana à medida que a quantidade de CNF da dieta aumentou de 25 para 54\%. No entanto, não houve diferença para a eficiência de síntese de proteína microbiana expressa em g de $\mathrm{N}$-microbiano/kg de $\mathrm{MO}$ verdadeiramente digerida no rúmen $(24,4)$ ou g de $\mathrm{N}$-microbiano/kg carboidrato digerido no rúmen $(35,0)$.

Avaliando o efeito de fontes de nitrogênio com diferentes valores de degradabilidade ruminal em dietas com alta quantidade de carboidratos (mandioca e cevada) em cultura contínua, Devant et al. (2001) observaram os maiores valores de eficiência microbiana para as dietas contendo uréia e os menores para dietas contendo farinha de peixe e glúten de milho (fontes protéicas de baixa degradabilidade ruminal). Esses autores concluíram que, em dietas com níveis elevados de concentrado, a disponibilididade de nitrogênio pode limitar o crescimento microbiano, sendo interessante salientar que, para a fonte de amido utilizada neste experimento, também de elevada degradabilidade ruminal (farinha de varredura de mandioca), a maior DIVMS foi obtida com o teor de $60 \%$ de PDR na dieta.

Neste experimento, a alta degradabilidade ruminal da farinha de varredura pode ter liberado uma quantidade de energia suficiente para tornar o nitrogênio limitante nos níveis de PDR mais baixos.

Logicamente, o incremento no nível de PDR das dietas pode aumentar a digestibilidade da MS sem que ocorra necessariamente aumento na atividade microbiana, principalmente em dietas contendo uréia, de elevada solubilidade. Contudo, neste trabalho, a equação quadrática obtida indicou a possibilidade de efeito de sincronização entre a disponibilidade de nitrogênio e de energia, visto que houve um nível de PDR no qual a digestibilidade foi máxima, decrescendo em seguida.

Este efeito concorda com os resultados obtidos na literatura para a utilização da farinha de varredura de mandioca na alimentação de ruminantes. Avaliando o efeito de rações compostas, com quatro fontes energéticas (milho, casca de mandioca, raspa de mandioca e farinha de varredura de mandioca) sobre as digestibilidades total e parcial em bovinos holandeses, Caldas Neto et al. (2000) observa- ram maior digestibilidade ruminal do amido (\% do total digerido e \% do que chega ao compartimento) para a ração contendo farinha de varredura de mandioca em comparação àquela contendo milho. Zeoula et al. (2002) também observaram que a ração contendo farinha de varredura de mandioca e farelo de soja como fonte protéica apresentou a menor digestão ruminal da $\mathrm{PB}$ e as menores concentrações de $\mathrm{N}-\mathrm{NH}_{3}$ no líquido de rúmen, além de maior eficiência microbiana aparente.

De modo geral, diversos trabalhos comprovam que a utilização de fontes de proteína de alta degradabilidade com fontes de amido de alta degradabilidade ruminal acarretam aumento na eficiência microbiana e, conseqüentemente, maior fluxo de proteína para o intestino delgado (Poore et al., 1993; Zinn, 1993a, b). Outros autores citam esse maior aporte protéico como um dos responsáveis pelo aumento da concentração da proteína no leite de animais alimentados com fontes de amido de alta degradabilidade ou fontes processadas.

$\mathrm{O}$ efeito quadrático também pode estar relacionado às exigências microbianas por aminoácidos, mais especificamente os de cadeia ramificada (leucina, isoleucina e valina) ou seus respectivos ácidos graxos de cadeia ramificada resultantes da desaminação.

Grinswold et al. (1996), avaliando o efeito de diferentes fontes protéicas em cultura contínua, observaram que o fornecimento de peptídeos em subtituição à uréia acarretou aumento na digestibilidade da FDA, na produção total de AGV e nas concentrações molares de isobutirato, isovalerato e valerato, demonstrando que a microbiota apresenta exigências de nitrogênio superiores à disponibilidade de amônia.

Assim, o comportamento quadrático observado pode ser explicado, pois, com o aumento do nível de PDR da dieta, houve maior disponibilidade de nitrogênio para atividade microbiana, elevando a degradabilidade da MS, como resultado da energia disponibilizada pela fonte de amido. Contudo, como os níveis de PDR foram elevados pela adição da uréia, os ácidos graxos de cadeia ramificada ou peptídeos podem ter se tornado limitantes para atividade microbiana a partir de determinada concentração de PDR.

Não foi observado efeito dos níveis de PDR sobre o consumo de MS (Tabela 4). Os valores médios foram semelhantes aos registrados por Marques et al. (2000), de 8,3 kg/ dia, para dieta contendo farinha de varredura de mandioca como fonte energética, enquanto os valores de consumo de MS como \% PV foram superiores aos observados por esses autores, de 2,1\% PV, diferença relacionada ao maior peso vivo das novilhas utilizadas por esses autores.

Esta ausência de diferença no consumo de MS está de acordo com os resultados obtidos por Coomer et al. (1993), 
que, avaliando diferentes fontes protéicas, não observaram diferença no consumo de MS em novilhos consumindo dietas com diferentes níveis de PDR. Cervieri et al. (2001) também não obtiveram diferença no consumo de MS de novilhos alimentados com dietas contendo 61,69 e $77 \%$ de PDR e verificaram que o consumo em $\mathrm{kg} / \mathrm{dia}$ foi menor que o observado neste experimento, em decorrência do menor peso vivo dos animais $(240 \mathrm{~kg})$.

Também não foi observado efeito dos níveis de PDR sobre os consumos de MO, PB, CT, FDN e CNF. Os resultados observados para os consumos de MO e PB foram semelhantes aos obtidos por Marques et al. (2000), de 8,5 e 1,0 kg/dia, respectivamente, enquanto o CFDN foi superior, como conseqüência da maior quantidade de volumoso nas dietas.

Como não foi observada diferença no consumo de MS, a ausência de resultado no consumo de PB pode ser explicada pelo fato de as dietas terem sido isoprotéicas. Além disso, em todas as dietas, utilizou-se o mesmo nível de volumoso e, como fonte de amido, empregou-se a farinha de varredura de mandioca, o que, possivelmente, influenciou os resultados dos consumos de FDN, CT e CNF, que foram semelhantes entre as dietas (Tabela 3 ).

Houve efeito $(\mathrm{P}<0,05)$ dos níveis de PDR sobre o consumo de EE em \%PV, possivelmente em virtude do elevado teor de EE da farinha de peixe utilizada na ração com menor nível de PDR e da diferença no peso vivo dos animais entre os tratamentos.

Tabela 4 - Consumo médio diário de nutrientes (em kg de MS/dia e em \% PV) no período experimental

Table 4 - Average daily intake of nutrients expressed as amount ( $\mathrm{kg} \mathrm{DM} /$ day) and as percentage of body weight

\begin{tabular}{|c|c|c|c|c|c|}
\hline \multirow[t]{2}{*}{$\begin{array}{l}\text { Consumo } \\
\text { Intake }\end{array}$} & \multicolumn{4}{|c|}{$\begin{array}{l}\text { Dieta \%PDR } \\
\text { Diet \% RDP }\end{array}$} & \multirow[t]{2}{*}{$\begin{array}{l}\text { Regressão } \\
\text { Regression }\end{array}$} \\
\hline & 55 & 60 & 65 & 70 & \\
\hline \multicolumn{6}{|c|}{$\mathrm{kg} / \mathrm{dia}(\mathrm{kg} /$ day $)$} \\
\hline $\mathrm{MS}(D M)$ & 8,4 & 8,8 & 9,1 & 8,6 & $\mathrm{Y}=8,7$ \\
\hline $\mathrm{MO}(O M)$ & 7,8 & 8,2 & 8,6 & 8,0 & $\mathrm{Y}=8,1$ \\
\hline $\mathrm{PB}(C P)$ & 1,0 & 1,1 & 1,1 & 1,1 & $\mathrm{Y}=1,1$ \\
\hline $\mathrm{EE}(E E)$ & 0,2 & 0,2 & 0,2 & 0,2 & $\mathrm{Y}=0,2$ \\
\hline $\mathrm{CT}(T C)$ & 6,5 & 7,0 & 7,3 & 6,9 & $Y=6,9$ \\
\hline $\mathrm{FDN}(N D F)$ & 3,4 & 3,8 & 3,8 & 3,5 & $\mathrm{Y}=3,6$ \\
\hline $\mathrm{CNF}(N F C)$ & 3,2 & 3,0 & 3,5 & 3,4 & $\mathrm{Y}=3,3$ \\
\hline \multicolumn{6}{|c|}{$\% \mathrm{PV}(\%$ of $B W$ ) } \\
\hline $\operatorname{MS}(D M)$ & 2,8 & 2,9 & 2,7 & 2,6 & $\mathrm{Y}=2,7$ \\
\hline $\mathrm{MO}(O M)$ & 2,6 & 2,7 & 2,5 & 2,4 & $Y=2,6$ \\
\hline $\mathrm{PB}(C P)$ & 0,3 & 0,4 & 0,3 & 0,3 & $\mathrm{Y}=0,3$ \\
\hline $\mathrm{EE}(E E)$ & 0,07 & 0,06 & 0,06 & 0,05 & $*$ \\
\hline $\mathrm{CT}(T C)$ & 2,2 & 2,3 & 2,1 & 2,1 & $\mathrm{Y}=2,2$ \\
\hline $\mathrm{FDN}(N D F)$ & 1,1 & 1,2 & 1,1 & 1,1 & $\mathrm{Y}=1,1$ \\
\hline $\mathrm{CNF}(N F C)$ & 1,1 & 1,1 & 1,0 & 1,0 & $\mathrm{Y}=1,1$ \\
\hline
\end{tabular}

* $\hat{Y}=0,105-0,00071 \times \% P D R) ; R^{2}=0,7$.
Os níveis de PDR na dieta não afetaram o ganho médio diário (GMD) dos animais (Tabela 5). O resultado médio obtido (1,3 kg/dia) foi inferior ao observado por Marques et al. (2000) em novilhas (380 kg PV) consumindo dieta com farinha de varredura de mandioca (1,5 kg/dia). Esta diferença pode estar relacionada à menor quantidade de concentrado utilizada nas rações e ao menor peso vivo $d$ as novilhas, tornando o ganho proporcionalmente semelhante entre os dois experimentos.

Os resultados foram semelhantes aos relatados por Sampaio et al. (1998), que registraram ganhos médios de $1,2 \mathrm{~kg} / \mathrm{dia}$ ao fornecerem rações com diferentes fontes protéicas a bezerros desmamados.

A ausência de efeito está de acordo com os resultados obtidos por Coomer et al. (1993), que não observaram efeito da utilização de fontes de proteína não-degradável no rúmen (PNDR) sobre o ganho de peso médio diário de novilhos precoces. Sindt et al. (1993), trabalhando com bezerros castrados, também não observaram efeito da substituição da uréia por fontes de PNDR (farinha de sangue e farinha de penas) sobre o ganho de peso dos animais. Da mesma forma, Milton et al. (1997) não observaram diferença entre novilhos de ano recebendo uréia ou fontes de PNDR (farinha de sangue e glúten de milho).

Menores teores de PDR na dieta podem aumentar o aporte total de aminoácidos para o intestino, sem alterar o ganho de peso, graças ao balanço de aminoácidos. Esse efeito pode ocorrer nos experimentos envolvendo fontes de PNDR, como farinha de penas e glúten de milho. Huntington et al. (2001) observaram menor ganho de peso de novilhos em crescimento quando o farelo de soja foi substituído por farinha de glúten de milho, mesmo que o fluxo de aminoácidos para o duodeno tenha sido superior para a dieta com menor PDR, indicando que a composição de aminoácidos da proteína que escapa também deve ser considerada quando se avalia o efeito da PDR.

Fluharty et al. (1994), no entanto, observaram maior ganho de peso em bezerros castrados alimentados com rações com menores níveis de PDR. Cervieri et al. (2001), trabalhando com dietas com 61, 69 e 77\% de PDR, também observaram maior ganho de peso nos bezerros não-castrados alimentados com as dietas com baixos teores de PDR na fase de crescimento ( 240 a $350 \mathrm{~kg}$ ). Esses autores atribuíram este resultado ao atendimento adequado da maior exigência de proteína para ganho dos animais, visto que bezerros não-castrados e recém-desmamados apresentam maior cres cimento muscular e elevada exigência de proteína metabolizável. Assim, as rações com menor nível de PDR podem ter permitido maior fluxo de aminoácidos para o intestino delgado, com valor biológico adequado e, conseqüentemente, maior ganho de peso. 
Neste experimento, embora os níveis de PDR tenham sido ainda menores que aqueles utilizados por outros autores e a fonte de PNDR (farinha de peixe) tenha apresentado valor biológico adequado, o maior aporte de proteína intacta para o intestino delgado não foi suficiente para alterar o ganho de peso entre os tratamentos, o que pode estar relacionado às alterações na fermentação ruminal, visto que as rações com baixa PDR permitiram fluxo maior de proteína dietética, diminuindo, porém, a disponibilidade de amônia no rúmen.

A maior eficiência microbiana nos animais que receberam as rações com níveis mais elevados de PDR pode ter sido ocasionada pela sincronização entre a disponibilidade de energia e amônia no rúmen, em decorrência da elevada degradabilidade ruminal da fonte de amido utilizada (farinha de varredura de mandioca) (Zeoula \& Caldas Neto, 2001), favorecendo a síntese de proteína microbiana. Assim, o aporte final de aminoácidos para o intestino delgado pode ter sido semelhante entre os níveis de PDR utilizados, de modo que o fluxo de proteína dietética foi substituído por proteína microbiana.

Cervieri et al. (2001) salientaram a importância da sincronização na degradação das fontes energéticas e protéicas e sugeriram que o maior ganho de peso obtido para os animais recebendo dietas com menores níveis de PDR em seu experimento estejam relacionados à utilização de milho moído grosseiramente como fonte energética. Como o milho moído grosseiramente apresenta menor degradabilidade ruminal, pode não ter ocorrido disponibilidade suficiente de energia para a síntese microbiana na ração com maior teor de PDR.

Vargas Jr. et al. (2003) também não observaram efeito da utilização de fontes de nitrogênio com diferentes níveis de degradabilidade ruminal (uréia, farelo de soja e farinha de

Tabela 5 - Desempenho de novilhos em confinamento alimentados com diferentes dietas experimentais com amido de alta degradabilidade e níveis crescentes de proteína degradável no rúmen (PDR)

Table 5 - Performance of feedlot steers fed diets with starch source rapidly degraded in the rumen and with increasing levels of rumen degradable protein (RDP)

\begin{tabular}{|c|c|c|c|c|c|}
\hline \multirow[t]{2}{*}{ Item } & \multicolumn{4}{|c|}{$\begin{array}{c}\text { Dieta \%PDR } \\
\text { Diet \% RDP }\end{array}$} & \multirow[t]{2}{*}{$\begin{array}{l}\text { Regressão } \\
\text { Regression }\end{array}$} \\
\hline & 55 & 60 & 65 & 70 & \\
\hline $\operatorname{PVI}(I B W), \mathrm{kg}$ & 258,2 & 267,0 & 296,7 & 290,5 & \\
\hline $\operatorname{PVF}(F B W), \mathrm{kg}$ & 332,0 & 339,6 & 380,1 & 363,1 & \\
\hline GMD $(A D G), \mathrm{kg}$ & 1,2 & 1,2 & 1,4 & 1,2 & $\mathrm{Y}=1,3$ \\
\hline CAMS $(D M I G R), \mathrm{kg} / \mathrm{kg}$ & 7,1 & 7,2 & 6,6 & 7,0 & $\mathrm{Y}=7,0$ \\
\hline
\end{tabular}

PVI: peso vivo inicial; PVF: peso vivo final; GMD: ganho médio diário; CAMS: conversão alimentar da MS.

IBW: initial body weight; FBW: final body weight; ADG: average daily gain; DMIGR: DM intake/gain ratio. penas) sobre o ganho de peso de bezerros mestiços e concluíram que os animais alimentados com as dietas com uréia podem ter apresentado melhores resultados de eficiência microbiana e, conseqüentemente, o aporte de aminoácidos para o intestino delgado foi equilibrado pelo maior fluxo de aminoácidos microbianos. Do mesmo modo, as rações com farinha de penas hidrolisada possibilitaram maior absorção intestinal de proteína dietética, compensando a menor síntese microbiana e acarretaram resultados produtivos semelhantes.

Considerando o consumo de nutrientes observado e as exigências descritas pelo NRC (1996), o ganho médio diário deveria ser inferior ao obtido, mas, possivelmente, ocorreu ganho compensatório, como resultado do tamanho reduzido do período experimental.

Não houve efeito do nível de PDR sobre a conversão alimentar da MS (CAMS). O resultado médio (7,0:1) obtido foi semelhante ao observado por Marques et al. (2000), de 7,3:1, para novilhas mestiças alimentadas com dietas contendo farinha de varredura de mandioca. Coomer et al. (1993) não observaram efeito da utilização de farelo de soja aquecido e farelo de glúten de milho como fontes de PNDR sobre a eficiência alimentar de novilhos em crescimento. Milton et al. (1997) também não observaram efeito da substituição de uréia por farinha de sangue e glúten de milho.

Entretanto, Sindt et al. (1993), em estudo com animais após a desmama, observaram melhores resultados de eficiência alimentar nos animais recebendo fontes de PNDR até 41 dias de confinamento, mas não observaram, no entanto, efeito do nível de PDR após 72 dias de confinamento. Do mesmo modo, Cervieri et al. (2001) observaram melhor valor de conversão alimentar nos tratamentos com menor nível de PDR na fase 1 do experimento (primeiros 92 dias de confinamento), mas não verificaram efeito do nível de PDR na fase seguinte.

Estes resultados comprovam que a exigência protéica dos animais, possivelmente, está correlacionada às necessidades de PDR, visto que os animais mais jovens, em fase de crescimento, principalmente após a desmama, parecem responder melhor à utilização de dietas com menor nível de PDR. Neste experimento os animais estavam na fase final de crescimento, o que também pode ter acarretado ausência de efeito do nível de PDR sobre a conversão alimentar.

\section{Conclusões}

A utilizaçãode dietas com níveis crescentes de proteína degradável no rúmen, associada à fonte de amido de alta degradabilidade ruminal (farinha de varredura de mandioca) influenciou a digestibilidade in vitro da MS, compro- 
vando a possibilidade de existência de um nível de sincronização da liberação de nitrogênio e energia no rúmen que permita maior digestibilidade ruminal da dieta.

A utilização de dietas com teores crescentes de proteína degradável no rúmen, associada à fonte de amido de alta degradabilidade ruminal permitiu ganho de peso e conversão alimentar semelhantes em novilhos em crescimento.

\section{Literatura Citada}

CALDAS NETO, S.F.; ZEOULA, L.M.; BRANCO, A.F. et al. Mandioca e resíduos das farinheiras na alimentação de ruminantes: digestibilidade total e parcial. Revista Brasileira de Zootecnia, v.29, n.6, p.2099-2108, 2000.

CERVIERI, R.C.; ARRIGONI, M.D.B.; OLIVEIRA, H.N. et al. Desempenho e características de carcaça de bezerros confinados recebendo dietas com diferentes degradabilidades da fração protéica. Revista Brasileira de Zootecnia, v.30, n.5, p.1590-1599, 2001.

CHESTER-JONES, H.; STERN, M.D.; SU, A. et al. Evaluation of various nitrogen supplements in starter diets for growing Holstein steers and their effects on ruminal bacterial fermentation in continuous culture. Journal of Animal Science, v.68, n.10, p.2954-2964, 1990.

COMMER, J.C.; AMOS, H.E.; FROETSCHEL, M. et al. Effects of supplemental protein source on ruminal fermentation, protein degradation, and amino acid absorption in steers and on growth and feed efficiency in steers and heifers. Journal of Animal Science, v.71, n.10, p.3078-3086, 1993.

DEVANT, M.; FERRETZ, A.; CALSAMIGLIA, S. et al. Effect of nitrogen source in high-concentrate, low-protein beef cattle diets on microbial fermentation studied in vivo and in vitro. Journal of Animal Science, v.29, n.8, p.1944-1953, 2001.

EUCLYDES, R.F. Manual de utilização do programa SAEG (Sistema de Análise Estatística e Genética). Viçosa, MG: Universidade Federal de Viçosa, 1983. 59p.

FLUHARTY, F.L.; LOERCH, S.C.; SMITH, F.E. Effects of energy density and protein source on diet digestibility and performance of calves after arrival at the feedlot. Journal of Animal Science, v.72, n.6, p.1616-1622, 1994

FU, C.J.; FELTON, E.E.D; LEHMKUHLER, J.W. Ruminal peptide concentration required to optimize microbial growth and efficiency. Journal of Animal Science, v.79, n.5, p.13051312, 2001

GRISWOLD, K.E.; HOOVER, W.H.; MLLER, T.K et al. Effect of form of nitrogen on growth of ruminal microbes in continuous culture. Journal of Animal Science, v.74, n.3, p.483-491, 1996.

HOOVER, W.H.; STOKES, S.R. Balancing carbohydrates and proteins for optimum rumen microbial yield. Journal of Dairy Science, v.74, n.11, p.3630-3640, 1991.

HUNTINGTON, G.; POORE, M.; HOPKINS, B. et al. Effect of ruminal protein degradability on growth and $\mathrm{N}$ metabolism in growing beef steers. Journal of Animal Science, v.79, n.3, p.533-541, 2001 .

KLUSMEYER, T.H.; MCCARTHY JR., R.D.; CLARK, J.H. et al. Effects of source and amount of protein on ruminal fermentation and passage of nutrients to the small intestine of lactating cows. Journal of Dairy Science, v.73, n.11, p.3526-3537, 1990.

MARQUES, J.A.; PRADO, I.N.; ZEOULA, L.M. et al. Avaliação da mandioca e seus resíduos industriais em substituição ao milho no desempenho de novilhas confinadas. Revista Brasileira de Zootecnia, v.29, n.5, p.1528-1536, 2000.
MILTON, C.T.; BRANDT JR., R.T.; TITGEMEYER, E.C. et al. Effect of degradable and escape protein and roughage type on performance and carcass characteristics of finishing yearling steers. Journal of Animal Science, v.75, n.8, p.2834-2840, 1997.

MILTON, C.T.; BRANDT, R.T.; TITGEMEYER, E.C. Effects of dietary nitrogen source and concentration in high-grain diets on finishing steer performance and nutrient digestion. Journal of Animal Science, v.75, n.10, p.2813-2823, 1997.

NATIONAL RESEARCH COUNCIL - NRC. Nutrient requirements of beef cattle. Washington, D.C.: National Academy of Sciences, 1996. 242p.

NOCEK, J.E.; RUSSEL, J.B. Protein and energy as an integrated system. Relationship of ruminal protein and carbohydrate avaliability to microbial synthesis and milk production. Journal of Dairy Science, v.71, n.10, p.2070-2107, 1988.

POORE, M.H.; MOORE, J.A.; ECK, T.P. Effect of fiber source and ruminal starch degradability on site and extent of digestion in dairy cows. Journal of Dairy Science, v.76, n.10, p.22442259, 1993.

RUSSELL, J.B. Strategies that ruminal bacteria use to handle excess carbohydrate. Journal of Animal Science, v.76, n.9, p.19551963, 1998.

SAMPAIO, A.A.M.; BRITO, R.M.; VIEIRA, P.F. et al. Efeito da suplementação protéica sobre o crescimento, terminação e viabilidade econômica de bezerros mestiços Canchim confinados pós-desmama. Revista Brasileira de Zootecnia, v.27, n.4, p.823-831, 1998.

SILVA, D.J.; QUEIROZ, A.C. Análises de alimentos (métodos químicos e biológicos). 3.ed. Viçosa, MG: Editora UFV, 2002. $235 \mathrm{p}$.

SINDT, M.H.; STOCK, R.; KLOPFENSTEIN, T.J. et al. Protein sources for finishing calves as affected by management system. Journal of Animal Science, v.71, n.5, p.1047-1056, 1993.

VALADARES FILHO, S.C.; ROCHA JR., V.R.; CAPPELLE, E.R. Tabelas brasileiras de composição de alimentos para bovinos. 1.ed. Viçosa, MG: Editora UFV, 2002. 297p.

Van SOEST, P.J.; ROBERTSON, J.B.; LEWIS, B.A. Symposium: methods for dietary fiber, neutral detergent fiber and nonstarch polysaccharides in relation to animal nutrition. Journal of Dairy Science, v.74, n.11, p.3583-3597, 1991.

VARGAS JR., F.M.; SANCHEZ, L.M.B.; PASCOAL, L.L. et al. Desempenho de bezerros de corte alimentados com diferentes fontes protéicas associadas à silagem de sorgo colhida em duas alturas de corte. Revista Brasileira de Zootecnia, v.32, n.3, p.690-698, 2003.

ZEOULA, L.M.; CALDAS NETO, S.F. Recentes avanços em amido na nutrição de vacas leiteiras. In: SIMPÓSIO INTERNACIONAL EM BOVINOCULTURA DE LEITE, 2., 2001, Lavras. Anais... Lavras: UFLA-FAEPE, 2001. p.249-284.

ZEOULA, L.M.; CALDAS NETO, S.F.; BRANCO, A.F. Mandioca e resíduos das farinheiras na alimentação de ruminantes: $\mathrm{pH}$, concentração de $\mathrm{N}-\mathrm{NH}_{3}$ e eficiência microbiana. Revista Brasileira de Zootecnia, v.31, n.3, p.1582-1593, 2002.

ZINN, R.A. Influence of processing on the feeding value of barley for feedlot cattle. Journal of Animal Science, v.71, n.1, p.3-17, 1993a.

ZINN, R.A. Influence of processing on the feeding value of oats for feedlot cattle. Journal of Animal Science, v.71, n.10, p.2303-2318, 1993b.

ZINN, R.A.; OWENS, F.N. Ruminal escape protein for lightweight feedlot calves. Journal of Animal Science, v.71, n.8, 1677 1687, 1993. 